

LONDON SATURDAY 2 OCTOBER 1971

\title{
Haemorrhage in the Newborn
}

The clotting factors in the blood that are dependent on vita$\min \mathrm{K}$ for their synthesis (factors II (prothrombin), VII, IX, and $\mathrm{X}$ ) are at a lower concentration in normal newborn infants than in adults.

The concentration falls still lower during the first few days of life, usually reaching a nadir on about the third day. It then rises again slowly towards adult levels, which are reached at a few weeks of age. When this physiological and transient deficiency of clotting factors is exaggerated, it may result in spontaneous haemorrhage, especially from the gastrointestinal tract or the umbilical stump. It is to this syndrome of bleeding due to vitamin- $K$ deficiency that the term "haemorrhagic disease of the newborn" is now restricted.

This multiple clotting-factor deficiency has several contributory causes. Body reserves of vitamin $\mathrm{K}$ are low at birth, especially in infants who are "small for dates". The lack of a bacterial flora in the gut during the first few days of life may also contribute to a deficient intake of the vitamin, and in some instances hepatic insufficiency may result in defective synthesis of clotting factors from vitamin $K$. There is no doubt, however, that the chief cause of haemorrhagic disease of the newborn, and of the deficiency of vitamin-K-dependent clotting factors which underlies it, is a dietary deficiency of vitamin $\mathbf{K}$ resulting chiefly from the small amount of the vitamin in breast milk.

H. Dam and colleagues ${ }^{1}$ showed that cow's milk contained about $6 \mu \mathrm{g}$ of vitamin $\mathrm{K}$ per $100 \mathrm{ml}$, but human milk only $1.5 \mu \mathrm{g}$ per $100 \mathrm{ml}$, and several groups of workers have found a profound fall in prothrombin and associated factors in breast-fed infants. J. M. Sutherland and colleagues ${ }^{2}$ showed clearly, from a study of over 3,000 full-term infants, that haemorrhagic disease of the newborn was typically a disease of otherwise healthy breast-fed infants who had not received parenteral vitamin $\mathrm{K}$, and that $100 \mu \mathrm{g}$ of vitamin $\mathrm{K}$ was as effective as $5 \mathrm{mg}$ in the prevention of bleeding in such infants. W. J. Keenan and colleagues ${ }^{3}$ have recently shown that the prothrombin time 24 hours after the beginning of feeding with cow's milk was no longer than that of infants given vitamin $\mathrm{K}$ at birth, whereas in infants receiving either breast milk or sterile water it remained prolonged. They recommend the parenteral administration of $100 \mu \mathrm{g}$ of vitamin $K_{1}$ to every newborn infant shortly after birth. This dose is without risk to the infant and can be relied on to eliminate hypoprothrombinaemic bleeding. When haemorrhage occurs in an infant so treated, some other cause must be sought.
The phrase "haemorrhagic disease of the newborn" was introduced by $\mathrm{C}$. W. Townsend ${ }^{4}$ long before the development of modern knowledge of the haemostatic mechanism. He used it to distinguish a form of generalized bleeding restricted to the neonatal period, and leading either to death or to complete recovery, from the lifelong disorder of haemophilia. The subsequent identification of vitamin-K deficiency as one important cause of neonatal haemorrhage, and the adoption of Townsend's term to describe this particular syndrome, should not be allowed to blind us to the several other causes of bleeding in newborn infants. They include the group of coagulation defects observed in sick and premature infants and classified by A. J. Aballi and S. De Lamerens $s^{5}$ as "secondary haemorrhagic disease of the newborn." Evidence has subsequently accumulated that many such cases result from disseminated intravascular coagulation, ${ }^{6}$ which may occur in infants born after abruptio placentae, ${ }^{7}$ in severe birth asphyxia and hypothermia, ${ }^{8-10}$ and in rhesus isoimmunization. ${ }^{11}$ Failure to distinguish this type of haemostatic abnormality from that due to vitamin-K deficiency has probably been largely responsible for the lack of agreement in the past on the value of prophylactic vitamin $\mathrm{K}$ in the newborn.

Vitamin-K deficiency is the most likely diagnosis when gastrointestinal haemorrhage occurs, usually on the second or third day of life, in an otherwise healthy breast-fed fullterm infant who has not previously received vitamin $\mathbf{K}$. A possible source of confusion is "false melaena", due to the passage of maternal blood swallowed in utero, which can be distinguished by means of an alkali denaturation test on the haemoglobin in the stool. The prothrombin time in vitamin-K deficiency will be greatly prolonged, or the thrombotest result less than $10 \%$, while the platelet count and plasma fibrinogen are within normal limits and the thrombin time is usually not significantly prolonged. Treatment with $1 \mathrm{mg}$ of vitamin $K_{1}$ parenterally will control the bleeding and correct the clotting-test results within about 24 hours, and blood transfusion will not usually be necessary.

This clinical and haematological picture may be contrasted with that of disseminated intravascular coagulation, which usually presents with generalized bleeding, often including intracranial haemorrhage, in a severely ill premature infant on the first day of life. Respiratory distress, hypothermia, and shock are commonly present, and the prognosis is grave. While the prothrombin time or thrombotest result is likely 
to be abnormal, it will probably be less so than in vitamin-K deficiency, but will be associated with thrombocytopenia, fibrinogen deficiency, and probably with the presence of fibrin degradation products in the plasma. Vitamin-K therapy will be without avail, and exchange transfusion with fresh heparinized blood offers the best hope of success.

Now that these two chief types of haemorrhagic disorder of newborn infants have been clearly distinguished, it can be seen that simple deficiency of the vitamin-K-dependent factors can be virtually eliminated by the parenteral administration of as little as $100 \mu \mathrm{g}$ of vitamin $\mathrm{K}$, immediately after birth. The adoption of this policy would have the additional advantage, by eliminating one type of haemorrhagic disorder, of facilitating the rapid diagnosis of the other.

\footnotetext{
1 Dam, H., Glavind, J., Larsen, E. H., and Plum, P., Acta Medica Scandinavica, 1942, 112, 210

Sutherland, J. M., Glueck, H. I., and Gleser, H., American fournal of Diseases of Children, 1967, 113, 524

${ }^{3}$ Keenan, W. J., Jewett, T., and Glueck, H. I., American fournal of Diseases of Children, $1971,121,271$

4 Townsend, C. W., Archives of Pediatrics, 1894, 11, 559

5 Aballi, A. J., and De Lamerens, S., American Fournal of Diseases of Children, 1962, 104, 475.

- Boyd, J. F., Archives of Disease in Childhood, 1967, 42, 401.

7 Edson, J. R., Blaese, R. M., White, J. G., and Krivit, W., Fournal of Pediatrics, 1968, 72, 342 .

8 Skyberg, D., and Jacobsen, C. D., Acta Paediatrica Scandinavica, 1969, $58,83$.

Chessells, J. M., and Wigglesworth, J. S., Archives of Disease in Child-

hood, 1970, 45, 539 .

${ }^{10}$ Chessells, J. M., and Wigglesworth, J. S., Archives of Disease in Childhood, 1971, 46, 253

1 Chessells, J. M., and Wigglesworth, J. S., Archives of Disease in Childhood, $1971,46,38$.
}

\section{Aetiology of Bell's Palsy}

The facial nerve is the most frequently paralysed nerve in the body. Ever since Sir Charles Bell in 1821 established that the muscles of facial expression were under the control of a separate cranial nerve his name has been associated with all forms of facial palsy. Over the years other causes such as trauma, infection of the middle ear and mastoid bone, geniculate herpes, tumours along the intracranial roots, acoustic neuroma, stroke, and sarcoidosis have been recognized as causes of facial palsy. When these causes are not found the condition is referred to as idiopathic or Bell's palsy, and these cases constitute the vast maiority. ${ }^{12}$

From recent reports $^{3}$ on facial paralysis by $H$. $M$. El-Ebiary it would seem that there is a geographical variation in its prevalence. He has reported a clinical study of 580 cases of facial paralysis seen over a period of 12 months, over $90 \%$ of them diagnosed as Bell's palsy. The cases were seen in the department of physical medicine at the University Hospital in Alexandria covering a population of one and a half million people. He found the condition twice as common as in Cairo and 20 times that of a London teaching hospital. Though these figures are not strictly comparable, and it is not clear whether these are isolated figures for one year, the incidence is certainly very high.

The cause of paralysis, whether due to vasospasm after exposure to cold or draughts, ${ }^{4}$ vascular insufficiency and secondary ischaemia, ${ }^{5-7}$ or some form of viral infection, ${ }^{89}$ is unknown. Pathologically it seems likely that oedema and subsequent compression of the nerve trunk within the rigid, bony fallopian canal owing to circulatory disturbance is a most likely cause. El-Ebiary's evidence is against the theory of vasospasm due to exposure to cold or draughts, as he found that only $5.4 \%$ of his patients gave a history of exposure to cold and the highest incidence of the disease was in the warm autumn months from August to December, the peak being in December. The age and sex of his patients differed from those in other series. ${ }^{7} 10 \mathrm{He}$ found that the disease was more frequent in the first two decades of life than later and that females, who usually stay indoors, were affected more frequently than males. From the study of his 528 cases of Bell's palsy and from comparing them to other series he postulates that the cause is infection, resulting from either bathing in polluted sea water or droplet transmission. The lesion might be due, he suggests, to a specific infective neuritis or to spread of inflammation from a latent, non-suppurative otitis media, and considers that the high incidence of the disease in younger patients, who are prone to upper respiratory and middle-ear infections, further supports his theory. However, no clinical, bacteriological, or radiological evidence is offered at present to support it.

Other authors have also favoured the theory of infection. Sir William Gowers, ${ }^{4}$ discussing Bell's palsy, said "neuritis is the cause of the common facial paralysis due to cold and often termed rheumatic." G. A. Dalton ${ }^{8}$ found evidence that some cases of Bell's palsy are due to zoster infection. U. Leibowitz, ${ }^{9}$ reporting a large series also from the Middle East, found that cases occurred in clusters, and he suggested that these groups of cases were dependent on each other or on unknown factors which affected them all. He called them "epidemics of Bell's palsy," and their occurrence supported the hypothesis of a viral infection as the cause. It would be interesting to know the incidence in Egypt of other infectious diseases and their relation with facial paralysis, if any. The Bell's palsy was recurrent in $9 \%$ of El-Ebiary's patients, and the recurrence rate was twice as common in females as in males. He offers an interesting suggestion that premenstrual retention of water might be a predisposing factor, but some evidence of that would be welcome. As the incidence of diseases in the first two decades of life is higher in females than in males, it might be worthwhile to study their nutritional and haematological status as well as any association with other infectious diseases in the population.

Once again the value of electrodiagnostic tests was confirmed. Though these tests from the fourth day onwards can differentiate between conduction block and nerve degeneration, it is difficult to predict the degree of recovery likely to be achieved in patients with degeneration.

As long as the cause is unknown, treatment remains empirical. Fortunately most patients with conduction block recover completely. But what should be done in the first three days? So far the only controlled clinical trial to show any statistically significant effects of treatment in Bell's palsy was that reported by $\mathrm{D}$. Taverner and colleagues, ${ }^{11}$ who stated that ACTH was effective. Now in a controlled trial of intramuscular corticotrophin and oral prednisolone published this week in the B.M.F. (page 20) Drs. Taverner, S. B. Cohen, and B. C. Hutchinson concluded that oral prednisolone is the treatment of choice for Bell's palsy. What should be noted too is the recent report $^{12}$ that the natural course of Bell's palsy cannot be influenced favourably by surgical decompression of the facial nerve in the second or third week after the onset of paralysis.

\footnotetext{
${ }^{1}$ Cawthorne, T., and Wilson, T., Archives of Otolaryngology, 1963, 78,

429.
2 Jongkees, L. B. W., Archives of Otolaryngology, 1965, 81, 518.
} 